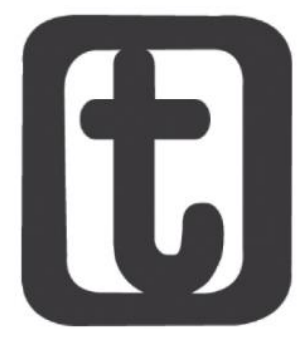

\title{
QUESTÃO AMBIENTAL NO SERVIÇO SOCIAL, AFINAL DO QUE SE TRATA?
}

\author{
Environmental issue in social work, what is it?
}

\section{Raquel Mota Mascarenhas*}

http://orcid.org/0000-0003-2410-3429

\section{RESUMO}

O objetivo desse artigo é apresentar uma análise histórica do estudo da questão ambiental na área de conhecimento do Serviço Social brasileiro, visando identificar i) a emergência da temática ambiental e ii) quais conceitos de questão ambiental são cunhados e/ou mais referenciados. A partir da pesquisa bibliográfica, pode-se aferir que a temática tem um percurso de construção de cerca de três décadas, visto ser na década de 1990 quando ocorre o início da produção teórica, indo da ausência de formulação de um conceito de questão ambiental à sua construção, que é permeada por um conjunto de disputas e tensionamentos.

\section{PALAVRAS-CHAVE}

Estado de arte. Questão ambiental. Serviço social.

\section{ABSTRACT}

The objective this article is historical analysis study environmental question in Brazilian Social Work identify i) emergency environmental thematic and ii) which are environmental question built and/or most referenced. From bibliographic research, concluded thematic started after three decades, at $1990 s$ first production, from absence formulation going construction environmental question concept permeated disputes and tensions.

\section{KEYWORDS}

State art. Environmental question. Social work.

\footnotetext{
* Assistente Social. Doutoranda em Serviço Social na Universidade Federal do Rio de Janeiro. Docente do curso de Serviço Social da Universidade Federal de Ouro Preto. Rua do Catete, n. 166, Mariana (MG), CEP.: 35420-000.E-mail: rmmascarenhas.ufop@gmail.com.

DOI 10.22422/temporalis.2021v21n41p381-396 copiar e redistribuir o material em qualquer suporte ou formato, bem como adaptar, transformar e criar a partir deste material para qualquer fim, mesmo que comercial. O licenciante não pode revogar estes direitos desde que você respeite os termos da licença.
} 


\section{INTRODUÇÃO}

A temática ambiental foi integrada progressivamente a área de conhecimento do Serviço Social, constituindo currículos ${ }^{1}$ no bacharelado; extensão ${ }^{2}$, disciplinas 3 , linhas ${ }^{4}$ e grupos de pesquisa ${ }^{5}$ em programas de pós-graduação; eixos $^{6}$ de comunicação científica no Congresso Brasileiro de Assistentes Sociais (CBASS) ${ }^{7}$, e Encontro Nacional de Pesquisadores em Serviço Social (ENPESS) ${ }^{8}$. Além disso, a Associação Brasileira de Ensino e Pesquisa em Serviço Social constrói o Grupo Temático de Pesquisa9 em Questão Agrária, Urbana, Ambiental e Serviço Social - cujo objetivo é

[...] aprofundar a construção de fundamentos teórico-metodológicos, em uma perspectiva de totalidade, para embasar a análise crítica das expressões da questão social no âmbito da questão agrária, urbana e ambiental, em sua materialidade na realidade brasileira, bem como sobre as estratégias de intervenção profissional nestes campos (ASSOCIAÇÃO BRASILEIRA DE ENSINO E PESQUISA EM SERVIÇO SOCIAL, 2012, p. 463464).

Bem como, a questão ambiental tem apresentado desafios ético-políticos à categoria, que tem se posicionado, por exemplo, via Conselho Federal de Serviço Social na perspectiva de "[...] fortalecimento da articulação com os movimentos sociais e da reflexão no âmbito da formação e do exercício profissional quanto à necessidade histórica da luta pelo direito ao meio ambiente" (CONSELHO FEDERAL DE SERVIÇO SOCIAL, 2012).

Diante a esse patamar de acúmulo da categoria, a análise das produções na área do Serviço Social acerca da temática ambiental tem sido objeto de investigação em nível de pós-graduação, culminando na produção de pesquisas denominadas estado

\footnotetext{
1 Dentre o currículo de 107 cursos de graduação, 81 (76\%) com disciplina sobre questão urbana, agrária e/ou ambiental (NUNES; SARMENTO, 2018).

${ }^{2}$ Em 2017, dentre 34 programas de pós-graduação (PPG), 9 (26\%) com ações de extensão vinculadas a temática urbana, agrária e ambiental (ASSOCIAÇÃO BRASILEIRA DE ENSINO E PESQUISA EM SERVIÇO SOCIAL, 2018).

3 Entre 2013 e 2017, 12 (35\%) dos 34 PPG com disciplinas de temática ambiental (ASSOCIAÇÃO BRASILEIRA DE ENSINO E PESQUISA EM SERVIÇO SOCIAL, 2018).

${ }^{4}$ De 2002 a 2012, 3 (10\%) dos 30 PPG com linha de pesquisa com temática ambiental (SILVERA, 2015).

5 De 2013 a 2017, 29 grupos de pesquisa com temática ambiental vinculados a PPG (ASSOCIAÇÃO BRASILEIRA DE ENSINO E PESQUISA EM SERVIÇO SOCIAL, 2018).

${ }^{6}$ No ENPESS e CBASS a temática ambiental constitui eixo de trabalho (ASSOCIAÇÃO BRASILEIRA DE ENSINO E PESQUISA EM SERVIÇO SOCIAL, 2018).

7 O CBAS, trianual, é o maior evento do Serviço Social brasileiro e constitui um fórum de reflexão, debate e deliberação da agenda das entidades nacionais - CFESS/CRESS, ABEPSS e ENESSO.

${ }^{8}$ O ENPESS, bianual, é um espaço de socialização de pesquisas e experiências profissionais, contribuindo à formação continuada, produção científica e técnica.

9 Os GTP's são um espaço de elaboração, produção e circulação do conhecimento, organizado por pesquisadores da área de Serviço Social e afins (ASSOCIAÇÃA BRASILEIRA DE ENSINO E PESQUISA EM SERVIÇO SOCIAL, @2020).
} 


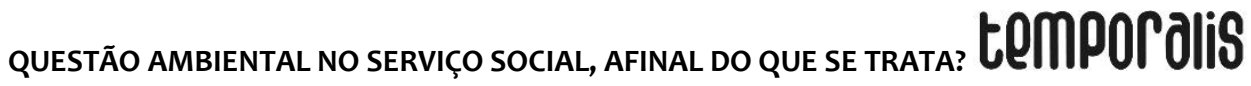

da $\operatorname{arte}^{10}$. Estas, por serem um panorama, constituem-se como fonte de coleta de dados bibliográficos para esse estudo - cujas produções foram localizadas no Catálogo de Teses e Dissertações da Coordenação de Aperfeiçoamento de Pessoal de Nível Superior (CAPES), limitando-se a programas de pós-graduação na Área 32 Serviço Social, utilizando os descritores de busca ambiental, socioambiental, ecologia, natureza e considerando a autoria de assistentes sociais.

As cinco produções analisadas são todas dissertações de mestrado, sendo os principais dados coletados dispostos na seção seguinte. Posteriormente, apresentamos a análise em que destacamos i) a emergência da temática ambiental e ii) quais conceitos de questão ambiental são cunhados e/ou mais referenciados. Por fim, o artigo apresenta algumas considerações sobre o estudo desenvolvido.

\section{O ESTADO DE ARTE ACERCA DA QUESTÃO AMBIENTAL}

As produções observadas analisam o acúmulo teórico acerca da temática ambiental na área do Serviço Social brasileiro e todas expressam vinculação a perspectiva teórico-metodológica marxista. Primeiramente, Deborah Cristina Corrêa, em sua dissertação ${ }^{11}$ intitulada $O$ debate ambiental no Serviço Social: construindo novos caminhos ou reatualizando velhos paradigmas?, analisa os Anais CBAS, no período de 1992 a 2007.

Ela identifica que a temática ambiental ocorre pela primeira vez no $7^{\circ} \mathrm{CBASS}$, em 1992, e, posteriormente, em 1998, no $9^{\circ}$ CBASS é estabelecido um eixo de apresentação de trabalho específico ao tema. Nesse universo, localizou o total de 54 trabalhos e aferiu que a maioria advém da região norte e nordeste (UFAM ${ }^{12}$ e UFPE ${ }^{13}$ ), devido "[...] a existência de grandes fontes de recursos naturais, o que leva consequentemente a uma maior atenção ao tema pelas universidades" (CORRÊA, 2010, p. 86). Além disso, conclui que “[...] o discurso do desenvolvimento sustentável mostrou-se presente na apreensão da problemática ambiental pelos assistentes sociais que são chamados a atuar frente a projetos de 'responsabilidade social', ou para contribuir nos processos de avaliação de impactos socioambientais" (CORRÊA, 2010, p. 77). Entretanto, pontua que a abordagem é acrítica, pois a sustentabilidade ambiental e social é vislumbrada no marco do capitalismo, instaurando

[...] um hiato entre aquilo que pensa e o que faz o assistente social, que ao intervir no campo ambiental, tomando por base o conceito de desenvolvimento sustentável, tenta atuar na minimização das manifestações da questão social e o resultado de seu trabalho é também a minimização do conflito entre capital e trabalho; a manutenção do status quo, a perpetuação das formas de exploração do homem e da natureza condicionados a um patamar aceitável, sem perspectivas de

\footnotetext{
${ }^{10} \mathrm{O}$ estado de arte visa mapear uma temática determinada a fim de inventariar, descrever e analisar a produção acadêmica (FERREIRA, 2002, p. 258).

${ }^{11}$ Orientada por Prof. Dr. Pedro Novais e apresentada em 2010 ao Programa de Pós-Graduação em Serviço Social da Universidade Federal de Juiz de Fora.

${ }^{12}$ Universidade Federal do Amazonas (UFMA).

${ }^{13}$ Universidade Federal de Pernambuco (UFPE).
} 
transformação social, e sim de adequação, em uma atitude conservadora à ordem social capitalista (CORRÊA, 2010, p. 80).

Corrêa destaca que essa abordagem do desenvolvimento sustentável, embora não seja tendência endógena a profissão - pois, advém do discurso hegemônico global expresso, por exemplo, na Conferência das Nações Unidas sobre o Meio Ambiente e o Desenvolvimento (conhecida como Eco-92 ou Rio-92), na Agenda 21, e na Convenção-Quadro das Nações Unidas sobre Mudança do Clima, realizadas em 1992 -, constitui uma ameaça ao projeto ético-político crítico do Serviço Social. Contudo, identifica um único trabalho divergente nos Anais do $10^{\circ} \mathrm{CBAS}^{14}$, em que há reflexão crítica ao desenvolvimento sustentável. Assim, conclui que "[...] o debate ambiental no Serviço Social é um caminho em construção [...]” (CORRÊA, 2010, p. 86), marcado por dois movimentos no interior da produção, crítico e conservador, ou seja,

[...] constatou-se que o Serviço Social vem ao mesmo tempo construindo novos conhecimentos sobre a temática ao estender o campo de abordagens e conexões entre a questão ambiental e a questão social e, por outro lado e no mesmo movimento contraditório, vem reatualizando velhos paradigmas ao absorver o discurso do desenvolvimento sustentável e aceitar seus pressupostos de adequação da degradação ambiental a um patamar considerado aceitável, dentro dos marcos da sociedade capitalista (CORRÊA, 2010, p. 86).

Para a autora a temática ambiental se dá de forma relacional às expressões da "questão social" (IAMAMOTO, 2001; NETTO, 2001), em que apresenta duas abordagens acerca da questão ambiental. No que tange a tratá-las como distintas, a autora afirma que "[...] existem nexos centrais entre a questão ambiental e a questão social. Ambas possuem sua gênese e conformação a partir do modo de produção e reprodução capitalista e suas formas de exploração e dominação" (CORRÊA, 2010, p. 41). Entretanto, explicita que a questão ambiental pode ser uma das expressões da "questão social" quando torna-se "[...] um campo de interesses conflituosos e divergentes, quando representa o antagonismo de interesses contraditórios de parcelas da sociedade que lutam pela decisão sobre a apropriação e uso dos bens e recursos naturais" (CORRÊA, 2010, p. 33). Assim, define que

\begin{abstract}
A questão ambiental, uma das configurações da questão social na contemporaneidade, tem um recorte, classista e social, onde a população pobre é, não só submetida de forma mais insidiosa aos riscos negativos da degradação ambiental, como também expropriada de qualquer direito de escolha ou decisão sobre a apropriação, exploração e uso dos recursos naturais existentes, numa forma de alienação própria e inerente a constituição desta sociedade (CORRÊA, 2010, p. 41).
\end{abstract}

Em suma, na visão da autora, “[...] a questão ambiental se apresenta aos assistentes sociais como uma das particularidades assumidas pela questão social na contemporaneidade, por isso, passível de apropriação e discussão" (CORRÊA, 2010, p. 48).

\footnotetext{
${ }^{14} \mathrm{O}$ trabalho intitulado Serviço Social e Meio Ambiente: um diálogo em construção, cuja autoria é suprimida no trabalho de Corrêa (2010).
} 


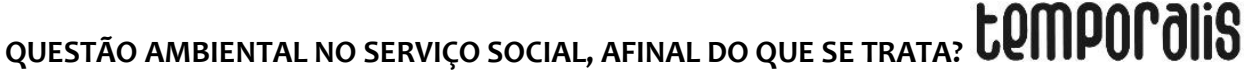

Outra contribuição é a de Jéssica Aparecida Pereira, quando em sua dissertação ${ }^{15}$ de mestrado intitulada $A$ produção de conhecimento sobre a questão ambiental no Serviço Social: análise dos ENPESS e CBAS no período de 2012 a 2016, analisou os Anais do CBAS e do ENPESS. Ela considerou os trabalhos dispostos na modalidade comunicação oral do eixo Questão agrária, urbana e ambiental, no ENPESS 2012, 2014, 2016; Questão urbana, agrária e meio ambiente: luta pela terra e condições de vida, no CBAS 2013; e Questão agrária, urbana, ambiental e serviço social, no CBAS 2016.

Nos Anais do ENPESS, localizou o total de 66 artigos que abordavam a questão ambiental - 29 em 2012, 23 em 2014, 14 em 2016 - portanto, do total de 3.357 trabalhos dentre os três Anais analisados, apenas 1,96\% abordavam o tema. Além disso, é a partir de 2006 (X ENPESS) que a questão ambiental passa a ser um tema do sub-eixo Questão Agrária, Questão Urbana e Sócio-ambiental. Em relação ao CBAS, do total de 35 artigos localizados, 17 foram em 2013 e 18 em 2016. Portanto, do total de 2.547 trabalhos constante dos Anais, a autora identifica que apenas 1,37\% abordavam a temática ambiental. Diante a esse quantitativo, Pereira aferi que é insipiente o tratamento teórico que a profissão remete a questão ambiental e, ao analisar o total de 101 trabalhos, oriundos dos CBAS e ENPESS, a autora

[...] constatou que o Serviço Social vem construindo novos conhecimentos acerca das conexões existentes entre a questão ambiental e a questão social e, por outro lado, no mesmo movimento contraditório, vem reatualizando velhos paradigmas, ao absorver o ideário ético do "desenvolvimento sustentável" e aceitar suas premissas de uma suposta conciliação entre: desenvolvimento econômico e degradação ambiental (PEREIRA, 2018, p. 146).

Para a autora, a produção da categoria acerca da questão ambiental está nos marcos iniciais, carecendo de estudos que ultrapassem a crença supraclassista e apreendam a relação entre questão ambiental e sociedade capitalista.

Além das aferições de Pereira (2018), observamos nos dados apresentados pela autora que os trabalhos analisados fazem uso da terminologia questão socioambiental, além da questão ambiental. Ela destaca a presença de ambas dentre as palavras-chave mais utilizadas, sendo a segunda mais citada que a primeira. Entretanto, não elenca a questão socioambiental para análise ${ }^{16}$, sendo ausente a problematização das convergencias e/ou dissonância diante ao uso da questão ambiental.

\footnotetext{
15 Orientada por Profa. Dra. Cristina Simões Bezerra e apresentada em 2018 ao Programa de PósGraduação em Serviço Social da Universidade Federal de Juiz de Fora.

${ }^{16}$ As categorias analíticas foram: "[...] a) Concepção e entendimento sobre a relação serviço social e questão ambiental; b) Observações acerca da relação entre a concepção profissional e a intervenção retratada no artigo; c) Relação/ vinculo observada entre profissional e sujeitos atendidos; d) Concepção de profissão: significado e importância do serviço social inserido no contexto da questão ambiental; e) Concepção dos profissionais sobre questão ambiental; f) Concepção dos profissionais sobre questão social e g) Desafios descritos no contexto do trabalho" (PEREIRA, 2018, p. 91).
}

Temporalis, Brasília (DF), ano 21, n. 41, p. 381-396, jan./jun. 2021. | ISSN 2238-1856 
No que tange a concepção de questão ambiental que norteia sua dissertação, observamos o alinhamento a divergentes formulações. Uma dessas é a contribuição de Maria das Graças e Silva (2010), pois Pereira afirma que a questão ambiental se refere "[...] ao conjunto de manifestações da destrutividade da natureza - cujas raízes encontram-se no desenvolvimento das relações de propriedade" (SILVA, 2010, p.82, apud PEREIRA, 2018, p.81). Entretanto, a autora também defende que "a questão ambiental constitui uma das expressões da questão social ${ }^{17}$ que demandam a intervenção profissional do serviço social na contemporaneidade" (PEREIRA, 2018, p.101) e, por fim, postula que "[...] nessa conjuntura na qual os problemas ambientais são socialmente produzidos pelo capital, a questão social é redimensionada e metamorfoseia-se em questão socioambiental" (PEREIRA, 2018, p. 101). Em suma, expõe:
A emergência do termo socioambiental é determinada, conforme Veiga (2007), pelo reconhecimento recente e incipiente da comunidade científica e sociedade em geral '[...] sobre os riscos e as incertezas que as sociedades enfrentarão por conta da degradação ambiental' (VEIGA ${ }^{18}, 2007$, apud BRITO, 2013). A legitimação desse neologismo não resulta de uma mera junção entre os termos social e ambiental, mas deve-se ao reconhecimento de que as mudanças sociais estão estruturalmente vinculadas relacionadas às mudanças ocorridas na relação homem- natureza, à medida que se reconhece que os reflexos do modelo de desenvolvimento adotado afetam diversas dimensões da vida em sociedade, dentre estas a saúde pública (PEREIRA ${ }^{19}$, 2014) (PEREIRA, 2018, p. 120).

Por sua vez, a autora Silvana Crisóstomo da Silva, apresenta a dissertação 20 intitulada PRODUÇÃO DE CONHECIMENTO DO SERVIÇO SOCIAL SOBRE A QUESTÃO AMBIENTAL: uma análise de seus fundamentos teórico-metodológicos e ídeo-políticos. Ela analisa artigos com ênfase na questão ambiental dispostos no eixo temático Questão Agrária, Urbana, Ambiental e Serviço Social nos Anais do XII (2010) e XIII (2012) ENPESS, bem como na Revista Katálysis, edição 2012, v.15, n.1, intitulada Relações Sociais, Desenvolvimento e Questões Ambientais.

O total de 44 artigos selecionados para análise são de autoria de assistente sociais e localizados através dos descritores: questão ambiental, meio ambiente, desenvolvimento sustentável, degradação/devastação ambiental, educação ambiental, sustentabilidade e conflitos socioambientais. Com base nesses critérios, a autora localizou 10 e analisou 03 artigos da Katálysis e, nos Anais do ENPESS, localizou 117 artigos, sendo 80 em 2010 e 37 em 2012 - dos quais analisou 15, em 2010, e 26, em 2012.

\footnotetext{
17 Utilizando as postulações de lamamoto (2001) e Netto (2001).

18 Não foi possível identificar as contribuições de Veiga (2007), utilizadas por Lady Mara Lima de Brito, no artigo Promoção da saúde e questão socioambiental: a interface entre saúde e ambiente, publicado nos Anais do XIV CBASS, em 2013.

$19 \mathrm{O}$ artigo A questão ambiental e os desafios ao serviço social e ao projeto ético-político profissional, publicado nos Anais do XIV ENPESS, em 2014, é de autoria de Mariana Figueiredo de Castro Pereira.

${ }^{20}$ Orientada por Prof. ${ }^{a}$ Dr. ${ }^{a}$ Maria das Graças e Silva e apresentada em 2015 ao Programa de PósGraduação em Serviço Social da Universidade Federal de Pernambuco.
} 
Em relação ao perfil das produções analisadas, aferiu que “[...] reitera-se o pressuposto de que as regiões geográficas que mais concentram os conflitos socioambientais são também as que originam a maior produção de conhecimento do Serviço Social sobre a questão ambiental" (SILVA, 2015, p. 102) - que são: região norte, com destaque para o estado de Amazonas, e nordeste. Além disso, categoriza as produções em dois agrupamentos no que tange aos fundamentos ídeo-políticos (ecossocialismo e o ecocapitalismo) ${ }^{21}$ e, dentre cada um desses, categoriza os fundamentos teórico-metodológicos ${ }^{22}$ que o constituem. Identifica que nas produções do Serviço Social nos ENPESS, predomina a orientação ídeo-política da ecodemocracia, portanto, preponderando o ecocapitalismo, sendo o autor mais citado Enrique Leff. No que tange a Revista Katálysis, aponta para a expressão do ecossocialismo, mas também, do ecocapitalismo, em particular da ecodemocracia. Acerca dos fundamentos téorico-metodológicos, aferi a predominância do sincretismo científico ${ }^{23}$, que culminam na estrutura de colcha de retalhos que caracteriza as produções acerca da questão ambiental no campo do Serviço Social. De forma particular, no que tange aos artigos contidos nos Anais dos ENPESS, temse: "[...] a) criticidade sobre a constituição da questão social e suas expressões, que se esvaece quando o debate toma a questão ambiental; b) discrepâncias entre a análise de uma dada problemática socioambiental e a estratégia para seu enfrentamento, revelando aspectos conservadores" (SILVA, 2015, p. 117). Em relação aos artigos da Katálysis, aponta:

1) a individualização da questão ambiental, principalmente, quanto ao seu enfrentamento; 2) ao se discutir a relação sociedade e natureza se realizam críticas ao modelo de desenvolvimento vigente, quase sempre desvinculando-o das determinações do modo de produção capitalista; 3 )

\footnotetext{
${ }^{21}$ Para Silva (2015, p. 123), os blocos ídeo-políticos são: “a) ecossocialista - os que se baseiam no método materialista histórico e dialético e pautam a ruptura com a ordem do capital; b) ecocapitalistas - que se dividem em ecodemocratas, os que defendem a democracia como fundante na relação com a natureza, com ênfase na articulação entre ecologia e política; e os ecoirracionalistas que responsabilizam a modernidade e o capitalismo industrial pelo atual estágio de degradação ambiental, em busca de uma "nova racionalidade"

${ }^{22}$ Silva (2015) define que o fundamento teórico-metodológico do ecossocialismo "[...] se baseia no método materialista histórico dialético, subsidiando-se nas obras de Karl Marx, Friedrich Engels, István Mészáros, Alain Bihr, Guillermo Foladori, Bellamy Foster, Michael Löwy, François Chesnais \& Claude Serfati" (SILVA, 2015, p. 105-106), com influência da obra de Maria das Graças e Silva. O ecocapitalismo é subdividido entre ecodemocracia e ecoirracionalismo, cujo "[...] o ponto em comum é o apelo à dimensão política na 'resolutividade' da degradação ambiental” (SILVA, 2015, p. 108-109); em que na ecodemocracia "[...] apela-se para a eficácia das políticas ambientais como fim último" (SILVA, 2015, p. 108-109); enquanto no ecoirracionalismo "as saídas para a crise se dão pela construção de uma consciência ambiental, a partir a universalização do saber ambiental" (SILVA, 2015, p. 115). A ecodemocracia conjuga "[...] as teses do conservacionismo, que também abarca 0 debate sobre desenvolvimento sustentável; e, da justiça ambiental [...]" (SILVA, 2015, p. 108), e os teóricos de referências são Antonio Carlos Diegues, Ignacy Sachs e Henri Acselrad. O ecoirracionalismo reuni "[...] argumentações sobre a dilapidação dos recursos naturais pairam na responsabilização do capitalismo industrial e na sociedade moderna. Para isso, se precisa construir uma nova 'racionalidade' ambiental e produtiva [...]" (SILVA, 2015, p. 115), tendo como principal expoente Enrique Leff.

23 Silva (2015) postula que o uso das correntes teóricas se dá por via do rigor teórico marxiana/marxista, positivista, fenomenológica e pós-moderna - e do sincretismo - suposta conciliação de teorias que são antagônicas em seus fundamentos, valores e orientações.
} 
por fim, a utilização de jargões típicos da tradição marxista e da direção social hegemônica do Serviço Social, mas sem reportar ao método materialista histórico e dialético para analisar a realidade recai na utilização de conceitos, na adequação destes à realidade (SILVA, 2015, p. 126-127).

Em completo alinhamento a concepção de questão ambiental cunhada por Maria das Graças e Silva (2010), a autora afirma a necessidade de superar o sincretismo através da ortodoxia do método de análise marxista e elenca quatro desafios à produção do Serviço Social acerca da questão ambiental:

1) Consolidar uma formação profissional fundamentada no arcabouço marxiano, [...] 2) Dar continuidade às investigações sobre a produção de conhecimento da profissão, [...] a fim de qualificar a atuação profissional; 3) [...] tratar teoricamente as inúmeras correntes que permeiam a produção de conhecimento da profissão sobre a questão ambiental, apontando suas matrizes e desvelando as distintas contribuições ao debate; 4) Desvelar os artifícios propagados pelo sincretismo científico e pela pós-modernidade (neoconservadorismo) [...] (SILVA, 2015, p. 135-136).

Outra contribuição advém de Vandenéia Bourckhardt, via dissertação ${ }^{24}$ intitulada Fundamentos da análise marxista sobre a temática ambiental e o Serviço Social, em que analisa as principais publicações da área até 2010 com vista a desenvolver "[...] um estudo conceitual dos fundamentos da análise marxista sobre o meio ambiente e como o Serviço Social se insere nessa discussão" (BOURCKHARDT, 2010, p. 96).

Dentre as fontes estão artigos da revista Serviço Social e Sociedade. A autora destaca o pioneirismo de Seno A. Cornely - no artigo Introdução à ecologia social, publicado em 1992 - que tece uma análise crítica do desenvolvimento sustentável ao "[...] apontar reflexões sobre a racionalidade produtiva dominante [...] e alertar sobre a necessidade de um modelo alternativo de desenvolvimento e de uma racionalidade ambiental" (BOURCKHARDT, 2010, p. 73). De outra forma, Jane Eyre G. Vieira - no artigo Educação para sustentabilidade: um pressuposto da participação comunitária na gestão ambiental das cidades de 2002 - expõe a gestão ambiental das cidades, articulando a questão urbana e ambiental, destacando a importância da educação ambiental, ainda que responsabilize o indivíduo e elenque as políticas ambientais como soluções. E, por fim, Eugênia Cesconeto e Marli Roesler - no artigo Limites de mensurabilidade dos indicadores ambientais no processo de conhecimento e de gestão ambiental de 2007 - que ratificam a importância da pesquisa para a atuação na área ambiental.

Bourckhardt destaca outra pioneira, Joaquina Teixeira de Andrade - no artigo Desenvolvimento Sustentado e Meio Ambiente, constituinte do Curso de Capacitação promovido pelo CFESS em 1997 - ao “[...] propiciar informações básicas sobre o surgimento da questão ambiental e sua vinculação ao movimento de reprodução ampliada do capital, tratando-se de uma demanda para a agenda de trabalho e

\footnotetext{
24 Orientada por Prof. Dr. Hélder Boska de Moraes Sarmento e apresentada em 2010 ao Programa de Pós-Graduação em Serviço Social da Universidade Federal de Santa Catarina.
} 


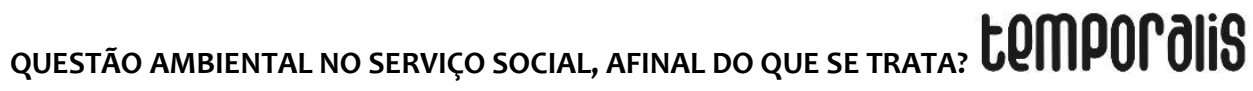

formação dos Assistentes Sociais [...]" (BOURCKHARDT, 2010, p. 73). Também, analisa o livro Serviço Social e Meio Ambiente - traduzido e publicado no Brasil, em 2005, pela editora Cortez - que apresenta um conjunto de artigos, organizado e produzido por autores latino-americanos (nenhum deles brasileiro), oriundos do I Congresso de Serviço Social e Meio Ambiente, realizado na Espanha, na Universidade de Huelva, em 2000.

A autora observa dois trabalhos de conclusão de curso. O primeiro de autoria de Raquel dos Santos - intitulado Meio Ambiente e Serviço Social e apresentado em 2007 na UFRJ - que analisa os principais periódicos do Serviço Social, os Anais dos CBAS e ENPESS, além de teses e dissertações, todos produzidos até 2006. No segundo - intitulado $O$ tratamento dado pela categoria profissional à questão ambiental: um estudo dos ENPESS e CBAS, apresentado em 2009 na UFSC - Bárbara Louise Carnevale analisa os Anais os CBAS e ENPESS entre 2000 a 2008 para identificar como os profissionais tem se apropriado do tema ambiental e quais as propostas de enfrentamento do tema para a profissão.

Apesar dessas incursões, Bourckhardt aborda com maior fôlego as dissertações e teses com temática do meio ambiente vinculadas aos Programas de Pós-Graduação em Serviço Social brasileiros. Ela conclui ser incipiente a produção, pois, no intervalo de dez anos (1998-2008), tem-se 24 (1,90\%) dissertações e $6(1,17 \%)$ teses do total de 1.263 e 512, respectivamente. Portanto, a produção sob o tema ambiental consistiu em $1,11 \%$ no período; presente em $50 \%$ dos programas, concentrada no eixo nortenordeste, com maior incidência na UFPE (10 produções), UFPA (6 produções) e PUCRio (3 produções).

Diante a essas bibliografias analisadas, a autora postula que "[...] ainda existem fragilidades dentro do Serviço Social na discussão da temática ambiental, sobretudo, na apropriação teórica que o Serviço Social faz dos autores que discutem o meio ambiente a partir da perspectiva marxista" (BOURCKHARDT, 2010, p. 96). Ela aponta que

\footnotetext{
O referencial teórico aqui construído mostra que existem posicionamentos diferenciados em relação à análise marxista sobre o meio ambiente. Existem os críticos que dirigem acusações a Marx e entendem que as discussões sobre o meio ambiente não tem lugar em suas obras, pois, o consideram "produtivista" e defensor do progresso e da tecnologia, como herdeiro do pensamento iluminista de sua época. Existem aqueles que defendem ter existido em Marx uma "visão ecológica", com destaque para a releitura realiza por Foster (2005) (BOURCKHARDT, 2010, p. 96).
}

Em seu estudo a autora não explicita uma conceituação da questão ambiental, apontando que a temática ambiental deve ser melhor aprofundada pela categoria levando em consideração os conceitos abordados em sua dissertação: metabolismo e alienação da natureza; relações de produção, forças produtivas, ideologia do progresso e padrão tecnológico; racionalidade ambiental; desenvolvimento, crescimento e meio ambiente, que orientam a formulação de leis e políticas ambientais. 
Outro estudo observado é a dissertação de João Paulo Borges da Silveira, intitulada Questão Ambiental e Sustentabilidade na produção de literatura do Serviço Social ${ }^{25}$, em que analisa as fundamentações teóricas das teses e dissertações com temática ambiental produzidas nos Programas de Pós-Graduação em Serviço Social entre 2002 a 2012. Observando título e palavras-chaves ${ }^{26}$, o autor elencou o total de 73 produções, das quais 59 dissertações (sendo na região sudeste 22, norte 16, nordeste 10 , sul 9, centro-oeste 2 ) e 14 teses (sudeste 6 , nordeste 5 , sul 2, centrooeste 1). Para ele, as regiões sudeste, nordeste e norte, por vivenciar maior incidência de conflitos ambientais, apresentam maior produção de teses e dissertações. Além disso, aponta que os três programas de pós-graduação com linha específica sobre questão ambiental (UFAM, UFPE e PUC-Rio) ${ }^{27}$ reúnem 32,8\% (24) das produções, sendo 19 dissertações e 5 teses.

Para análise o autor selecionou uma dissertação e uma tese de cada região, totalizando 05 dissertações e 04 teses. Aferiu que prevalece a ausência de uma clara opção e/ou coerência teórica - culminando em forte ecletismo teórico ${ }^{28}$ - e predomina uma perspectiva progressista ${ }^{29}$ - sendo que todas as cinco dissertações e uma tese foram analisadas como vinculadas à teoria marxista e, as demais três teses, à teoria sistêmica (pós-moderna) ${ }^{30}$.

Por fim, Silveira explicita que “[...] a questão ambiental é aqui compreendida nos termos definidos por Silva, como um 'conjunto de manifestações da destrutividade ambiental, resultantes da apropriação privada da natureza, mediadas pelo trabalho humano' (SILVA, 2010, p. 143)" (SILVEIRA, 2015, p. 25). Entretanto, o autor advoga à denominação da expressão socioambiental, como expõe:

O emprego da expressão socioambiental ocorre no sentido de caracterizá-la em termos distintos dos que a reduzem a uma dimensão 'natural', que não guardaria relação com a questão social, ou em termos de oposição entre o 'natural' e o 'artificial'. Trata-se, ao fim, de uma oposição do pensamento crítico antropocentrista a uma concepção

\footnotetext{
${ }^{25}$ Orientada por Prof. Dr. Hélder Boska de Moraes Sarmento e apresentada em 2015 ao Programa de Pós-Graduação em Serviço Social da Universidade Federal de Santa Catarina.

26 Palavras-chave utilizadas: meio ambiente, questão/debate ambiental, questão(ões) socioambiental(ais), socioambiental(ais) e sócio-ambiental(ais), desenvolvimento sustentável, sustentabilidade, sustentável(eis), ambiental(ais) e ambiente, injustiça/justiça ambiental(ais).

27 Dos 30 programas de pós graduação - em que 10 possui mestrado e doutorado e 20 apenas mestrado - somente 03 (10\%) dispõem de linhas de pesquisa sobre questão ambiental: Serviço Social, Diversidade Socioambiental e Sustentabilidade na Amazônia (UFAM); Capitalismo contemporâneo, questão ambiental e Serviço Social (UFPE); Questões socioambientais, urbanas e formas de resistência social (PUC-Rio). A UFPE e PUC-Rio possuíam mestrado e doutorado, a UFAM apenas mestrado.

${ }^{28} \mathrm{O}$ autor define ecletismo quando "[...] empregaram-se conceitos e categorias sem a preocupação com a caracterização dos mesmos, o que denota um desconhecimento da polissemia que caracteriza alguns conceitos no campo das ciências sociais" (SILVEIRA, 2015, p. 190).

29 Silveira (2015, p. 197) afirma que, "[...] com relação à postura 'progressista' mencionada, isso não significa de forma alguma que as abordagens sejam fundamentadas exclusivamente por uma perspectiva crítica [teoria marxista, em seu entendimento]".

30 Inclusive, apresentando críticas "[...] a direção majoritária do processo de formação em Serviço Social, que caracteriza como um 'grupo hegemônico' antes que ideias hegemônicas, que se apropriariam de uma determinada teoria e não se sensibilizariam para dar ouvidos a outras" (SILVEIRA, 2015, p. 197).
} 


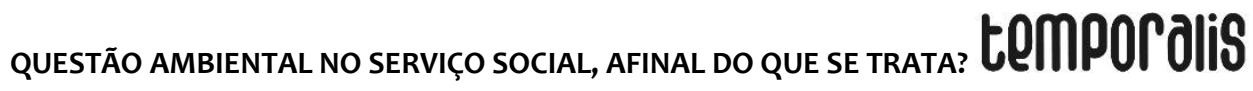

ecocentrista reducionista. Segundo a concepção crítica, a questão ambiental afeta e diz respeito à sociedade, na medida em que a natureza é apropriada segundo uma lógica desigual e cujos efeitos dessa forma de apropriação afetam também de forma desigual os grupos sociais envolvidos no processo (SILVEIRA, 2015, p. 25).

\section{TRÊS DÉCADAS DE PRODUÇÃO SOBRE A QUESTÃO AMBIENTAL}

Considerando as produções analisadas, pode-se aferir que a emergência da temática ambiental na área do Serviço Social ocorre na década de 1990, sendo os primeiros textos em 1992, nos Anais do VII CBASS ${ }^{11}$ e na revista Serviço Social e Sociedade ${ }^{32}$. Além disso, os espaços de debate da profissão abordaram especificamente o tema, com quase uma década de intervalo, pois, em 1998 no IX

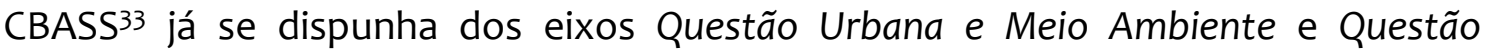
Agrária, Questão Indígena e Meio Ambiente; enquanto, apenas em 2006, no X ENPESS34 há inserção do sub-eixo Questão Agrária, Questão Urbana e Sócioambiental.

O entendimento consensual é de que a produção sobre questão ambiental é uma área em construção no Serviço Social, cujo interesse da categoria pela temática advém do reconhecimento de sua importância, por ser uma demanda profissional e, também, social, requerendo a qualificação da análise teórica. Isto é, não se trata de um movimento endógeno ao Serviço Social e, sim, reflete a vinculação orgânica da profissão à realidade social, onde se posiciona politicamente e sistematiza reflexões acerca da conjuntura mundial, nacional e regional. Isso porque, à época das primeiras produções, tem-se a emergência da discussão sobre a problemática ambiental, cujo enfrentamento hegemônico apresentado é o modelo capitalista de desenvolvimento sustentável. O que ocorre no bojo da organização de espaços de articulações internacionais, especialmente no Brasil, com a Conferência das Nações Unidas sobre o Meio Ambiente e o Desenvolvimento em 1992. Entretanto, dentre as produções da categoria sobre a temática ambiental, iniciado a cerca de trinta anos, percebe-se divergências na análise acerca do seu crescimento, ora considerado como inicial e insipiente ${ }^{35}$, ora como crescente e expressivo ${ }^{36}$.

Acerca da origem regional das produções, as análises convergem no entendimento de que são organicamente vinculadas as regiões com grande incidência de conflitos ambientais ${ }^{37}$. Em particular, historicamente, as regiões norte e nordeste ${ }^{38}$ são as

\footnotetext{
${ }^{31}$ Correa (2010) indica a predominância do viés conservador nas publicações analisadas, desde a primeira publicação que aborda o tema de Maria da Paz Araújo Cardoso, intitulado A Ilha do Mosqueiro, Turismo e Meio Ambiente: o reencontro da identidade. Sendo que localiza apenas uma produção com direcionamento crítico ao desenvolvimento sustentável, em 2001, no X CBASS.

32 Bourckhardt (2010) elenca o pioneirismo crítico Seno Antônio Cornely, em seu artigo Introdução à ecologia social, em que alerta para a falácia do desenvolvimento sustentado.

33 Como apresentou Corrêa (2010).

34 Como apresentou Pereira (2018).

35 Comungam o caráter inicial e insipiente da produção Pereira (2018) e Bourckhardt (2010).

${ }^{36}$ Concordam com a crescente expressividade da produção Silva (2015) e Silveira (2015).

37 Tanto Silva (2015), quanto Silveira (2012) aferem a relação entre a produção acerca da questão ambiental e a origem regional marcada por conflitos socioambientais.
} 
que mais produzem acerca da temática, mas tem-se observado o crescimento da produção na região sudeste ${ }^{39}$.

Em relação a quais conceitos de questão ambiental são cunhados na área de conhecimento do Serviço Social, as análises apresentadas nas dissertações convergem em alguns pontos. Primeiramente, as pesquisas são unânimes em explicitar a disputa entre as visões de mundo das classes sociais, burguesa e trabalhadora, presente desde as duas primeiras produções localizadas, ambas em 1992. Entretanto, divergem sobre qual a predominância dessas perspectivas ${ }^{40}$ no bojo da produção da categoria.

Outro ponto de convergência é o entendimento de que a construção do conceito acerca da questão ambiental é permeada por tensionamentos. A partir das análises das dissertações, pode-se aferir que a abordagem da temática ambiental no Serviço Social seguiu da ausência ${ }^{41}$ de formulação de um conceito de questão ambiental à sua construção ${ }^{42}$ permeada por disputas - com a proposição do termo socioambiental, ao invés de ambiental; o apontamento de que a questão (socio)ambiental deve ser considerada como uma das expressões da "questão social"; e a compreensão de que a "questão social" se metamorfoseia em questão socioambiental na contemporaneidade ${ }^{43}$.

Esse percurso tem sido marcado pela capilaridade ${ }^{44}$ da contribuição de Maria das Graças e Silva originada em sua tese de doutorado - intitulada Capitalismo contemporâneo e questão ambiental: o desenvolvimento sustentável e a ação do

\footnotetext{
${ }^{38}$ Todas as dissertações analisadas aferem a maior expressividade da produção acerca da questão ambiental originada na região nordeste e norte, exceto Silveira (2015) que aponta a região sudeste. ${ }^{39}$ Bourckhardt (2010) irá indicar que a produção de dissertações e teses acerca da questão ambiental, entre 1998 e 2008, se restringiu à $50 \%$ dos programas de pós-graduação, sendo que $85 \%$ no eixo norte e nordeste e $15 \%$ na região sudeste. Silveira (2015), por sua vez, aferiu o predomínio da região sudeste (40\%), seguido pelas regiões nordeste (30\%), sul (13,33\%), centro oeste (10\%), e norte $(6,66 \%)$ - e se somarmos os quantitativos da região norte e nordeste temos o total de $36 \%$, no período de 2002 2012. Ao comparar o resultado dos dois autores, pode-se aferir que a produção no sudeste cresceu, pois Silveira (2015) identificou 12 produções, enquanto Bourckhardt (2010) localizou apenas 03.

${ }^{40}$ Corrêa (2010) aponta para a predominância do conservadorismo nas produções acerca da questão ambiental no espaço do CBASS de 1992 a 2007, expressas na defesa do desenvolvimento sustentável nos moldes das organizações multilaterais. Silva (2015) concorda com essa aferição, uma vez que aponta o predomínio dos fundamentos ídeo-políticos do ecocapitalismo. Em contrário, a predominância do viés crítico é apontada por Pereira (2018), Bourckhardt (2010) e Silveira (2015).

${ }^{41}$ Bourckhardt (2010) não delimita um conceito de questão ambiental, mas aponta que a temática ambiental deve ser entendida no bojo do modo de produção capitalista, apresentando a contribuição de alguns intelectuais, como John Bellamy Foster, Michael Lowy e Enrique Leff.

${ }^{42}$ Corrêa (2010) cunha que a questão ambiental pode se constituir como expressão da "questão social".

${ }^{43}$ Silva (2015), Silveira (2015) e Pereira (2018) desenvolvem as suas análises a partir da ratificação e direcionamento da obra de Maria das Graças e Silva (2010). Entretanto, apenas Silva (2015) se restringe a delimitação da autora; enquanto Silveira (2015) e Pereira (2015) advogam pelo uso do termo socioambiental. Pereira (2018) também considera a questão ambiental como uma das expressões da "questão social" - assim como Corrêa (2010) - e advoga que a "questão social" se metamorfoseia em questão socioambiental na contemporaneidade.

${ }^{44}$ A capilaridade da obra de Silva (2010) é ratificada por Silva (2015) - ao analisar os Anais do ENPESS 2012 - e Silveira (2015) - que a aponta como maior referência dentre os autores do Serviço Social.
} 


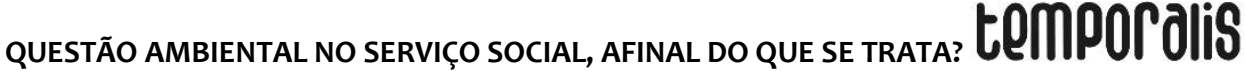

Serviço Social, defendida em 2008, em Recife, sob a orientação da Dr. ${ }^{a}$ Ana Elizabeth Mota, junto ao Programa de Pós-Graduação em Serviço Social da Universidade Federal de Pernambuco - que é publicada como livro em 2010 pela editora Cortez, cujo título Questão Ambiental e Desenvolvimento Sustentável: um desafio éticopolítico ao Serviço Social. Nessa obra, a autora estabelece como objetivo central ${ }^{45}$

[...] analisar a concepção de Desenvolvimento Sustentável como mecanismo de enfrentamento da "questão ambiental", realizando um exame crítico desde a sua colocação pelas agências internacionais, a sua conversão em programa de ação e, por fim, a sua instituição como prática de classe (SILVA, 2010, p. 40-41).

No bojo de sua pesquisa, Silva (2010) declara seu alinhamento ao marxismo e que compreende a “[...] apreensão da 'questão ambiental' como resultado da acentuação das contradições entre o desenvolvimento das forças produtivas e relações sociais de produção, próprias do capitalismo tardio [...]” (SILVA, 2010, p. 31). É a autora quem cunha a denominação de questão ambiental, refutando o termo crise ambiental conforme explicita:

\begin{abstract}
Dada a ambiguidade do termo 'crise ambiental' e os multiplos sentidos que porta - sendo no campo do pensamento crítico ora tratada como possibilidade de esgotamento das condições de reprodução do capital ora como ameça à humanidade e sobretudo às classes pauperizadas optamos pelo termo 'questão ambiental' aqui utilizado para referi-mo-nos ao conjunto das manifestações da destrutividade da natureza - cujas raizes encontram-se no desenvolvimento das relações de propriedade - e seus desdobramentos sócio-políticos, para os quais a ação do movimento ambientalista teve importância fulcral (SILVA, 2010, p. 82).
\end{abstract}

No que tange ao uso do termo, posteriormente ${ }^{46}$ Silva expõe que faz uso da nomenclatura "questão ambiental", porque "Entre aspas, posto que no nosso entendimento a problemática ambiental não se constitui num fenômeno natural ou numa mera consequência do desenvolvimento das sociedades; trata-se de uma 'questão' em função da natureza socialmente determinada da sua existência" (MOTA; SILVA, 2009, p. 47). Assim, a autora afirma que a gênese da questão ambiental "[...] encontra-se plasmada na apropriação privada dos elementos naturais e sua conversão em fatores de produção, mediada pelo uso da ciência e da tecnologia [...]" (SILVA, 2010, p. 234) e que se expressa como "[...] o aumento da poluição do ar e da água, a destruição da camada de ozônio, o acúmulo de lixo, o esgotamento dos recursos naturais não renováveis, o avanço da desertificação etc." (SILVA, 2010, p. 162). Afirma que se impõe como uma questão a ser enfrentada somente no final do século $X X$, quando a "[...] a dimensão política da 'questão ambiental’ foi provocada pelas organizações da sociedade” (SILVA, 2010, p. 227),

\footnotetext{
45 Ao tecer suas principais descobertas em relação a esse objetivo, afirma que "[...] o apelo a sustentabilidade e a ampla legitimação que obteve o conceito de Desenvolvimento Sustentável deriva do tratamento fetichizante que vem sendo adotado, esmaecendo-se o conteúdo classista da problemática ambiental e de suas possibilidades de superação" (SILVA, 2010 p. 42).

46 No artigo intitulado A questão ambiental e o contraditório discurso da sustentabilidade, com coautoria de Ana Elizabeth Mota, publicado em 2009 na revista Praia Vermelha.
} 
que é alvejada pela programática do desenvolvimento sustentável47, cujos "[...] os principais sujeito da construção [...] são os organismos internacionais" (SILVA, 2010, p. 177). Para ela, é imprescindível "[...] vincular a gênese da 'questão ambiental' à ordem burguesa e o discurso de sustentabilidade ao amplo movimento engendrado pelas classes sociais e pelo Estado para dar conta de seus efeitos catastróficos na etapa do capitalismo tardio" (SILVA, 2010, p. 33). Sendo que a supressão da questão ambiental é vista como impossível no capitalismo, pois não há "[...] qualquer margem de dúvida quanto a incapacidade de o sistema resolver as contradições gestadas por ele próprio" (SILVA, 2010, p. 240).

A autora, portanto, postula uma constituição sui generis da questão ambiental, propondo "[...] apreender a 'questão ambiental' como totalidade historicamente determinada” (SILVA, 2010, p. 30). Isto é,

É certo que no desenvolvimento de sua ordem sociometabólica o capital
opera inexorável e articuladamente na produção de mecanismo de
apropriação da natureza e de exploração do trabalho humano [...]; por
vias idênticas, transforma a natureza em 'condiçãa material da produção',
de tal sorte que tanto a depredação ambiental quanto a exacerbação da '
social' compóem uma unidade estrutural: a mercantilização da natureza e
a subsunção formal real do trabalho ao capital integram um mesmo
movimento destinado a assegurar as bases materiais e simbólicas do
processo de acumulação capitalista (SILVA, 2010, p. 231).

Assim, a autora concebe a questão ambiental distintamente à "questão social", mas aponta, em suma, para a "[...] estreita vinculação entre ambas [...]" (SILVA, 2010, p. 144), uma vez que "[...] ao mesmo tempo em que assegura a continua produção e reprodução da 'questão ambiental' - assim como ocorre com a questão social - o capital se empenha em atenuar as suas manifestações, administrando suas contradições [...]" (SILVA, 2010, p. 143).

Diante a análise tecida, ainda que a construção de conhecimento acerca da questao ambiental seja marcada por disputas no bojo da categoria de assistentes sociais, é inconteste que prepondera nas produções dessa categoria a contribuição de Maria das Graças e Silva.

\section{CONSIDERAÇÕES}

O saldo teórico constituído nas produções no Serviço Social aqui observadas explicita que "[...] não há como deixar de perceber que nós, assistentes sociais, somos autores e atores em toda a trajetória já percorrida" (MORAES; JUNCÁ; SANTOS, 2010, p. 450). Ou seja, a colaboração teórica das produções analisadas é essencial para que, hoje, possamos deslumbrar um estado de arte da questão ambiental em nossa categoria.

Mas não se pode esquecer da necessidade do aprimoramento intelectual como via para que o Serviço Social possa continuar a avançar no entendimento da questão

47 Silva (2010, p. 239) compreende o “[...] Desenvolvimento Sustentável - como expressão da tentativa de estabelecer mecanismo de controle da relação sociometabolica".

Temporalis, Brasília (DF), ano 21, n. 41, p. 381-396, jan./jun. 2021. | ISSN 2238-1856 


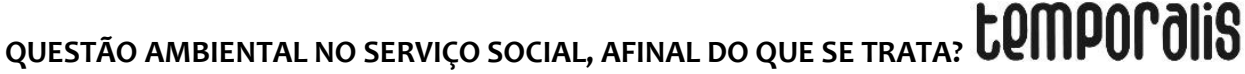

ambiental. Os desafios à produção do conhecimento destacados tangem, por exemplo, a apropriação das produções vinculadas a teoria social marxista acerca da temática ambiental (BOURCKHARDT, 2010), a fim de enfrentar o sincretismo científico e a pós-modernidade (neoconservadorismo), e, assim, prover análises qualificadas que possam nortear a atuação profissional (SILVA, 2015); e o desvelamento da fundação do capital - compreendendo a emergência da propriedade privada, do processo de acumulação primitiva, da mercantilização da natureza - e da sua crise contemporânea - abordando sua relação com o aumento da destruição ambiental (PEREIRA, 2018).

É nesse caminho que estimamos que esse artigo possa motivar a continuidade do acúmulo teórico acerca da questão ambiental e auxiliar na construção desse avanço da categoria. Pois "[...] não há como não admitir, portanto, nossa responsabilidade, não só em torno do ser, mas também no que se refere ao vir a ser do Serviço Social" (MORAES; JUNCÁ; SANTOS, 2010, p. 450).

\section{REFERÊNCIAS}

ASSOCIAÇÃO BRASILEIRA DE ENSINO E PESQUISA EM SERVIÇO SOCIAL (ABEPSS). Relatório GTP Questão Agrária, Urbana, Ambiental e Serviço Social Gestão 20172018. Brasília (DF): ABEPSS, 2018.

ASSOCIAÇÃO BRASILEIRA DE ENSINO E PESQUISA EM SERVIÇO SOCIAL (ABEPSS). Ementa do GTP Questão Agrária, Urbana, Ambiental e Serviço Social. Proposta de Ementa. Temporalis, Brasília (DF): ABEPSS, ano 12, n. 24, p. 461-466, jul./dez. 2012.

ASSOCIAÇÃO BRASILEIRA DE ENSINO E PESQUISA EM SERVIÇO SOCIAL (ABEPSS). GTPS. Brasília (DF): ABEPSS, O2020. Disponível em:

http://www.abepss.org.br/gtps.html. Acesso em: 24 abr. 2020.

BOURCKHARDT, Vandenéia. Fundamentos da análise marxista sobre a temática ambiental e o serviço social. 2010.Dissertação de Mestrado, Programa de PósGraduação em Serviço Social, Universidade Federal de Santa Catarina, Florianópolis, 2010.

CONSELHO FEDERAL DE SERVIÇO SOCIAL (CFESS). CFESS Manifesta do Dia Mundial do Meio Ambiente. Brasília (DF), 5 jun. 2012.

CORRÊA, Deborah Cristina. O debate ambiental no Serviço Social: construindo novos caminhos ou reatualizando velhos paradigmas? 2010. Dissertação (Mestrado em Serviço Social)-Faculdade de Serviço Social, Universidade Federal de Juiz de Fora, Juiz de Fora, 2010.

FERREIRA, Norma S. de Almeida. As pesquisas denominadas "estado da arte". Educação \& Sociedade, São Paulo, v. 23, n. 79, ago. 2002.

IAMAMOTO, Marilda Vilela. Questão social no capitalismo. Temporalis, n. 3, 2001. 
MORAES, Carlos A. de Souza; JUNCÁ, Denise C. de Moura; SANTOS, Katarine de Sá. Para quê, para quem, como? Alguns desafios do cotidiano da pesquisa em serviço social. Serviço Social \& Sociedade, São Paulo, Cortez, n. 103, jul./set. 2010.

MOTA, Ana Elizabete; SILVA, Maria das Graças e. A questão ambiental e o contraditório discurso da sustentabilidade. Praia Vermelha, Rio de Janeiro, v. 19, n. 2, jul./dez. 2009.

NETTO, José Paulo. Cinco notas a propósito da "questão social". Temporalis, Brasília (DF), n. 3, 2001.

NUNES, Letícia Soares; SARMENTO, Hélder Boska de Moraes. O SERVIÇO SOCIAL E A QUESTÃO SOCIOAMBIENTAL. In: ENCONTRO NACIONAL DE PESQUISADORES EM SERVIÇO SOCIAL, 16., 2018, Vitória. Anais [...]. Vitória: Ufes, dez. 2018.

PEREIRA, Jéssica Aparecida. A produção de conhecimento sobre a questão ambiental no serviço social: análise dos ENPESS e CBAS no período de 2012 a 2016. 2018. Dissertação (Mestrado Serviço Social)-Faculdade de Serviço Social, Universidade Federal de Juiz de Fora, Juiz de Fora, 2018.

SILVA, Maria das Graças e. Questão ambiental e desenvolvimento sustentável: um desafio ético-político ao Serviço Social. São Paulo: Cortez, 2010.

SILVA, Silvana Crisostomo da. Produção de conhecimento do serviço social sobre a questão ambiental: uma análise de seus fundamentos teóricometodológicos e ídeopolíticos. 2015. Dissertação (Mestrado Serviço Social)-Programa de Pós-Graduação em Serviço Social, Universidade Federal de Pernambuco, Recife, 2015.

SILVEIRA, João P. Borges da. Questão ambiental e sustentabilidade na produção de literatura do serviço social. 2015. Dissertação (Mestrado Serviço Social)-Programa de Pós-Graduação em Serviço Social, Universidade Federal de Santa Catarina, Florianópolis, 2015.

\section{Raquel Mota Mascarenhas}

Docente do curso de Serviço Social da Universidade Federal de Ouro Preto. Doutoranda no Programa de Pós-Graduação da Universidade Federal do Rio de Janeiro. Mestra pelo Programa de PósGraduação em Política Social da Universidade Federal do Espírito Santo. Graduada em Serviço Social pela Universidade Federal do Espírito Santo. Tem experiência na área de Serviço Social. Atualmente tem se dedicado aos temas: crítica da economia política, questão ambiental, pobreza, liberdade e barbárie. 